\title{
A virus as an icon: the 2020 pandemic in images
}

\author{
Julia Sonnevend ${ }^{1}$ \\ Published online: 6 October 2020 \\ (c) Springer Nature Limited 2020
}

\begin{abstract}
The 2020 coronavirus pandemic is puzzling from a visual point of view. There are millions of photographs published about the crisis every day, yet we can see the key actor, the virus, only in artistic representations. Most of us also have very restricted access to central sites of the crisis, as intensive care units, nursing homes, meat packing plants and prisons are often not available for photographic representation. At the same time, we are oversupplied by other images that try to capture the "essence" of the moment. This article analyzes three prevalent visual genres in connection with the ongoing pandemic: abstract representations of the virus and public responses to it, images of heroes and sinners, and photographs of the "stage": the iconic spaces including empty public buildings and busy domestic spaces. All these iconic representations try to grasp the "deep meaning" of the crisis through a particular scene or moment. Their expressive surfaces have become our key sources to imagine the coronavirus crisis, and to socially connect in a time of painful and prolonged physical distance.
\end{abstract}

Keywords Icon $\cdot$ Image $\cdot$ Representation $\cdot$ Visual $\cdot$ Pandemic $\cdot$ Coronavirus

The 2020 coronavirus crisis presents some unique visual challenges. There are millions of photographs published about this event every day, yet we cannot see the key actor: the virus. Most of us do not have access to the central sites of the crisis either. Intensive care units, nursing homes, meat packing plants and prisons are key locations of the crisis, often far away from cameras. Public health experts argue that if only we saw how the novel virus wrecked bodies, we would behave differently. Thus, there seems to be a fundamental problem with our not seeing what is happening in, and even around us.

The frustration of public health experts with people's lack of compliance also makes it clear that having powerful and expressive representations is not about the

Julia Sonnevend

jsonnevend@newschool.edu

1 Department of Sociology, The New School, 6 East 16th St., 79 5th Ave 9th Floor, New York, NY 10003, USA 
need for "spectacle" or "voyeurism". Without the ability to see and relate to this crisis, people will be unlikely to follow strict guidelines that interfere with their usual daily lives. Communicating and representing the crisis is thus not only about "talk", but also about "walk". As sociologist Jeffrey C. Alexander once put it, "icons root generic, social meaning in a specific and 'material' form" (2008, p. 782). Instead of being mere illustrations, they are entry points for public discussion and social contestation. Only through powerful communicative tools can those not in the medical profession comprehend a public health crisis, and ultimately act upon it.

Strangely, in the case of the 2020 pandemic while we are deprived of key visual experiences in relation to the coronavirus, we are also oversupplied by other images that try to capture the "essence" of the moment. On the New York Times website, there is a section that displays a permanent loop of "everyday" coronavirus-related photographs from Nepal to Hong Kong to the United States. And photographs pop up every second from a myriad of other sources internationally. The invisibility of the main actor has led to a flood of "indirect images" that struggle to stand for the event. In this strange visual ecosystem, what do these indirect or side photographs communicate to us? What are the stories, narratives and imaginaries they project and symbolically condense?

The visual supply is seemingly endless, but there are still a few key visual genres, a set of identifiable iconic repertoires. First, the artistic representation of the lead actor (the virus) and the abstract, and often confusing charts of our actions and their outcomes, for instance the "flattening curve." Then the images of the heroes (the essential workers, the efficient politicians, the successful scientists), and the sinners (whom you call a "covidiot" depends on your ideologies, but they can range from incompetent politicians to partyers in packed pools, to vigilantes, "libtards", the Gates Foundation, and so on). Finally, the "stage" of the crisis: the changing world around us, the empty airports and iconic buildings, people in masks in grocery stores, students taking exams at carefully placed tables, images of protests against stay-at-home-orders and systemic racism. The "stage" also includes the domestic spaces where we spend most of our time, the disorganized or over-organized apartments, the homes for heroic struggles with homeschooling and make-shift office work.

The virus is a unique performer. Invisible to the regular eye, yet widely represented in spectacular visuals. Perhaps the most well-known rendering of the virus came from the US-based Centers for Disease Control (CDC) (Fig. 1). On January 21, 2020, a day after the C.D.C. decided to activate its emergency operations center as a response to the developing coronavirus, two medical illustrators were tasked with the impossible: creating an "identity" for the virus that would "grab the public's attention" (Giaimo 2020). This was not the first time, Alissa Eckert and Dan Higgins had to draw something that was invisible to the human eye. Eckert, for instance, was particularly proud of her rendering of the bacteria that cause gonorrhea. But in this case, they aimed to produce something that they call a "beauty shot", "a detailed, solo close-up" that would be memorable and would inspire viewers to take the situation seriously. Even so, the illustrators did not expect the representation to reach a very wide audience and were genuinely surprised when the image suddenly spread around the world, like the virus it aimed to depict. 
Fig. 1 This illustration, created at the Centers for Disease Control, reveals ultrastructural morphology exhibited by coronaviruses. (Alissa Eckert, MSMI, Dan Higgins, MAMS, 2020) [CDC photograph in the public domain]

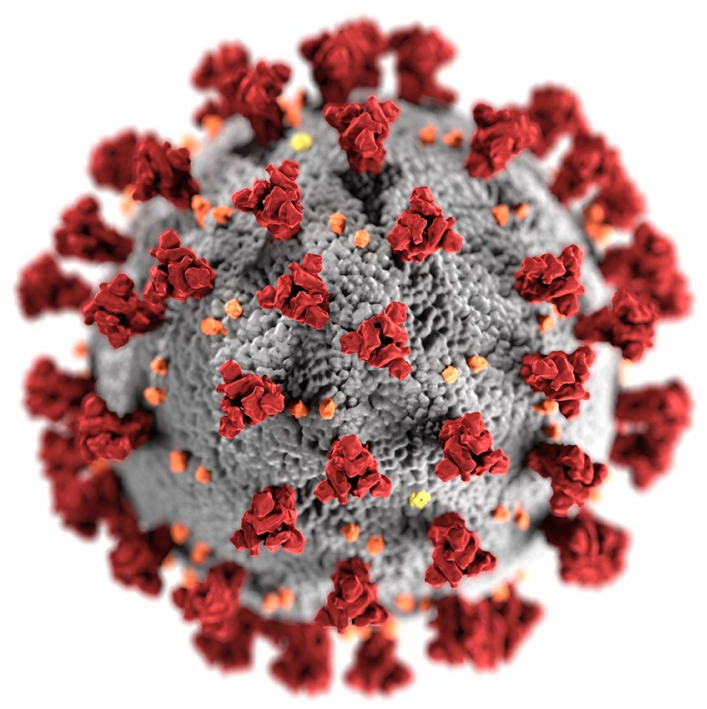

While this most often reproduced image of the coronavirus is increasingly familiar to many, most viewers do not actually know what they are seeing. What do the red, the yellow and the gray parts signify? What do other viruses look like? Are these the virus's "real" colors, or simply illustrative ones? A recent article called the famous CDC coronavirus representation a "3D rendering of a spiky fuzzball" and then attempted to interpret the distinct parts: the gray surface is a "spherical envelope that surrounds the nucleus of the virus", and it contains genetic material, the orange bits are "membrane proteins" which help us identify the virus and distinguish it from others, the yellow bits stand for "envelope proteins" which regulate virus replication and finally the red spikes are the virus' tools to attach to cells (Britt 2020). In addition to these relatively objective markers, there were also elements of the representation that required decisions from the illustrators. For instance, they chose a "stony texture", so that it seems like "you could actually touch" the virus, they also added details "to help display the gravity of the situation and to draw attention" (Giaimo 2020).

No representation, not even this relatively expressive one can translate the novel coronavirus to us. The virus's visual characteristics will mostly remain incomprehensible to the lay eye, regardless of how well the illustrators captured its details. But the representation's elusiveness has a key advantage: it makes the image easy to use in a wide variety of contexts. Since the image does not communicate much, it can relatively easily be added to a wide variety of texts. You will see the "spiky fuzzball" next to an article about whether or not to reopen colleges in the fall, articles on the mental health consequences of a pandemic, or a political op-ed criticizing the president's failing response to the crisis. Ultimately, the image of the coronavirus is highly versatile, because to non-experts it has very little meaning to offer.

The desire to present a representation that invites touch is particularly puzzling. Instead of scaring the viewer away, instead of the virus becoming a much-feared 
"beast," the coronavirus representation triggers admiration. Like a beautifully arranged flower bouquet, made from red roses, it is aesthetically pleasing. Its varied surfaces trigger the desire to approach, to explore, to find a connection, and ultimately: to touch. Of course, almost any representation of an unimaginable object is destined to attract attention and trigger exploration. Still, there is nothing in this coronavirus image that would make the viewer even a little bit fearful or cautious. In its aim to represent, the image manages to build a real connection between the viewer and the represented. It has become a representation of something the lay eye cannot see. But it does not symbolically condense the complex feelings and practices associated with the virus. It certainly does not trigger "social distancing"; its viewer rather craves proximity than distance.

If a representation of a virus was an unlikely candidate for iconicity, an abstract graph had even less "objective" chances. Most graphs are neither visually spectacular, nor easy to decipher. But abstract graphs have still played a central role in the representation of the 2020 pandemic crisis and became exceedingly popular with journalists. The most frequently reproduced graph shows the "flattening curve" which highlights that with social distancing measures the curve of the infection and hospitalization rates can be extended to a longer period of time, which in turn can help hospitals with the supply of hospital beds and critical equipment, for instance, ventilators for patients and protective gear for health care workers (Fig. 2). As one article in the New York Times put it, "the longer it takes for the coronavirus to spread to the population, the more time hospitals have to prepare" (Roberts 2020). The most likely origin of the chart was a CDC document from 2007, entitled "Goals of Community Mitigation", that recommended a series of mitigation practices in the event of a pandemic, including "social distancing", closing schools and limiting public gatherings. The colors have changed over time and a public health professor added a line representing "health care capacity" during the 2020 pandemic, but the core idea has remained the same (Weinberg 2020).

Many pointed out that the key feature of the "flattening the curve" graph is that it does not include numbers on the axes. Most of the time, not even the axes are defined. While meant to be a simplified representation, this graph is in fact highly abstract. "The flattening curve" graph provides the viewer with the illusion of being an insider of science who truly understands complex medical processes, but the graph is in fact every data scientist's nightmare. As one commentator put it, the flattening curve graph "was a work of the imagination, too artless to be art but lacking the hard empiricism we expect of science" (Weinberg 2020). Still, somehow both the iconic representation and the related slogan ("flatten the curve") have become

Fig. 2 "Flattening the curve." Adapted from the CDC by the Economist. Infographic created by Drew Harris, DPM, MPH

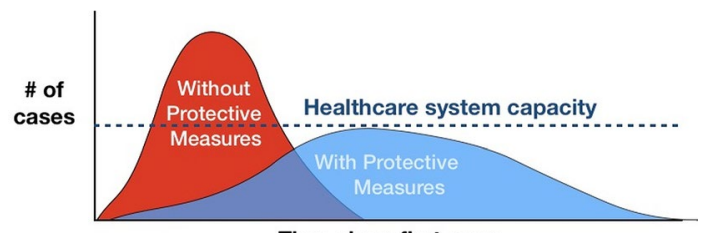

Time since first case Adapted from CDC / The Economist 
central features of the coronavirus discourse, perhaps because they provided people with agency and some control, and a set of clearly defined rules to follow.

Likely due to the limited iconic power of the lead actor, the virus, the roles of the "hero" and the "villain" are assigned to other performers. From early on in the crisis, healthcare workers and grocery store workers were framed as "essential workers", often described as "heroes". Cities all around the world have adopted rituals to clap and cheer for these workers every evening, creating a distinct celebratory music for those risking their lives. Homemade signs also popped up in front of grocery stores and hospitals, communicating simple and powerful messages such as "heroes work here" (Fig. 3).

Many also aimed to give actual "faces" to the generic category of "heroes." Frustrated by the non-distinctiveness of the category, essential workers took to social media to share images showing their distinct everyday experiences. A powerful example is the "COVID Nurses" [recently renamed as "Frontline Health Heroes"] Instagram account, which described itself as "diaries from the field" and "nurses fighting on the frontlines \& sharing their stories. It's not over till it's over." Nurses aimed to show their real faces on Instagram: exhausted, bruised from N-95 masks, annoyed by those who are not following public health guidelines. As Black Lives Matter protests also started to unfold during the pandemic, nurses began to post photographs where they were holding up signs connecting the pandemic to racial justice issues: "I save lives regardless of race, you take lives because of it", "White Supremacy is Deadlier Than COVID", and "Imagine If Nurses Ignored 'I Can't

Fig. 3 "Heroes Work Here" sign in front of a grocery store in Hillsdale, New York (Julia Sonnevend, June 9, 2020)

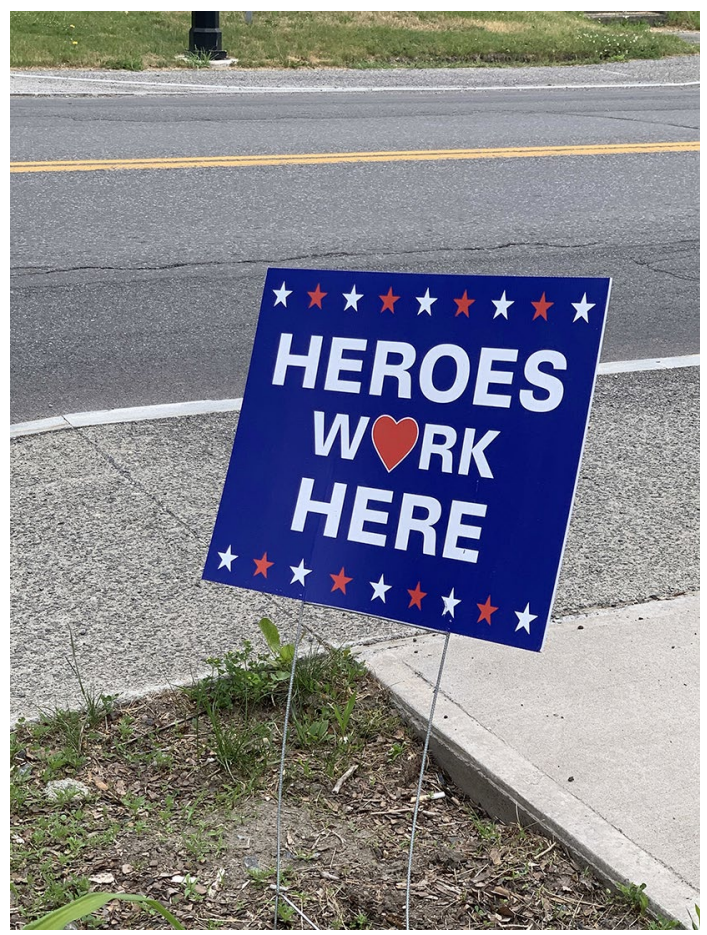


Breathe'-Black Lives Matter". One powerful photograph showed a white nurse with a sign "Nurses for Black Lives" next to an African-American nurse whose sign stated "Keep that same energy when you can't breathe! A Black RN" (Fig. 4). In this case the visual power of "COVID Nurses" that was developed during the early months of the pandemic provided the platform for expressive messages against racial inequality.

While the pandemic's heroes have been mostly "faceless" and nameless, covered by facemasks, standing for a broad and often abstract category, some particular iconic figures did emerge. Perhaps the most obvious icon is Dr. Li Wenliang, a 33-year-old ophthalmologist at Wuhan Central Hospital in China, who was an early whistleblower in the crisis and subsequently died from the novel coronavirus he was warning the world about (Yu 2020). Dr. Wenliang, a young, healthy, and successful doctor, stood out as a hero who took political, professional and health risks to avert the pandemic. Li was the father of a young boy and his wife was pregnant with their second child when he died, which made the tragedy even more relatable worldwide. His early-in-the crisis hospital photo where he was wearing a surgical mask, and his final photograph that he took while wearing an oxygen mask in a hospital bed have become the iconic representations of the early crisis (Fig. 5). The outrage over Li's death was - so far-the only time when the Chinese political leadership faced massive domestic backlash during the coronavirus crisis. His death became a top trending topic on Chinese social media, garnering more than one billion views (BBC 2020). Tens of millions Chinese social media users posted tributes to $\mathrm{Li}$, and many

Fig. 4 Nurses holding up signs at a Black Lives Matter protest, posted on the "COVID Nurses" Instagram site (Courtesy of Christel-Ann Augustin, June 7, 2020)

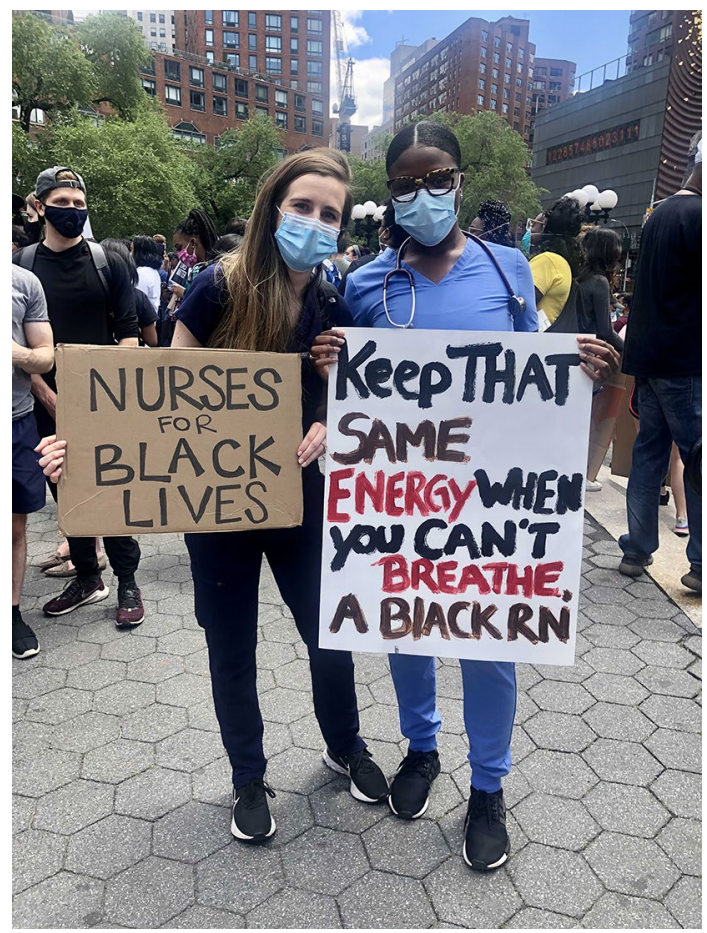


Fig. 5 One of the last photographs posted by Dr. Li Wenliang on Weibo on February 3, 2020 (REUTERS/Gan En Fund/ Li Wenliang)

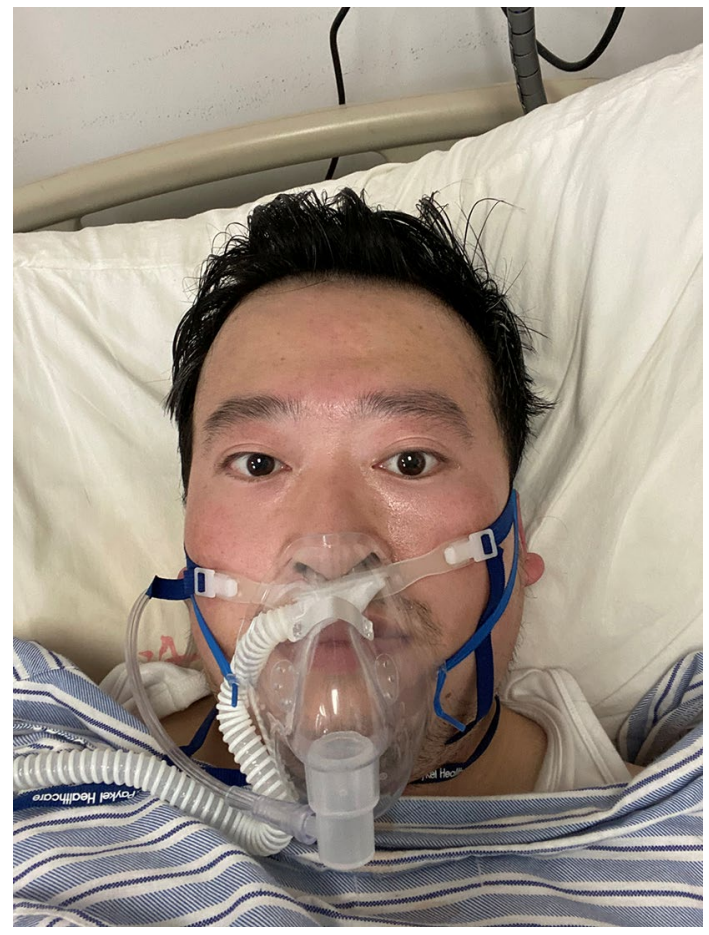

demanded systemic change and transparency in the country's pandemic response (Feng 2020). It is unlikely people would have felt a similar connection to him without his relatable photographs_-showing again the power of images in representing social meanings.

The popular framing of "heroes" has received ample criticism on social media, as many have argued that adequate pay and proper protective gear would be the real rewards for essential workers, while the language of heroism remains cheap. "Hero" is too broad a term that is easily applicable to everyone, without highlighting vast differences in who are "doomed" to be heroes in this case and who are more likely to escape to their second homes. Some analysts have also emphasized that while health care workers may have considered heroism as part of their job descriptions, this is hardly the case with grocery store, meat plant workers or teachers, who pictured a much less risky future for themselves.

Keeping a focus on heroes seemed almost too safe a bet for cultural institutions as well, as this framing was less likely to trigger controversy. For instance, a recent project entitled "Hold still", organized by the National Portrait Gallery in London and spearheaded by the Duchess of Cambridge, asked people to submit their portraits in relation to three categories: "helpers and heroes", "your new normal", and "acts of kindness". These categories already limit the viewer to a relatively positive take on the events, only the "your new normal" category has allowed for some interpretational flexibility. The description of the project also included its ultimate interpretation: "Hold Still will capture a snapshot of the people of the UK at this 
time, creating a collective portrait of our nation which will reflect resilience and bravery, humor and sadness, creativity and kindness, human tragedy and hope as we hold still for the good of others, and celebrate those who have continued so we can stay safe" (National Portrait Gallery 2020). Villains, disrupters and contrarians were absent in this description.

But villains seem to be the most exciting actors in the coronavirus drama, perhaps unsurprisingly. Identifying and shaming coronavirus villains is an international pastime on social media, and their prevalence even warranted a new term: "covidiot." According to Urban Dictionary: a covidiot is "someone who ignores the warnings regarding public health or safety" or "a person who hoards goods, denying them from their neighbors". The related examples are: "That covidiot is hugging everyone she sees." "Did you see that covidiot with 300 rolls of toilet paper in his basket?" Since there are so many unknowns about the virus, many take solace in the few knowns, for instance in the increasing evidence that face masks help in the prevention of asymptomatic spread (Prathner et al. 2020). This desire for control and community has also led to a wide-spread habit of vigilantism and public shaming. An early example was the attention over-crowded Florida beaches had received on social media. Another example was a packed pool-party at the Lake of the Ozarks in Missouri on Memorial Day weekend in 2020 that attracted extensive condemnation on social media. Images of partyers, standing in close proximity to each other without wearing masks, went viral on Twitter. Only one confirmed coronavirus case has emerged from this event; the excessive party has most likely not become a super-spreader event, but it has clearly become one of the iconic sites of "covidiot" shaming.

Early evidence increasingly shows the lower prevalence of transmission in outdoor settings, but packed outdoor events still tend to attract the public's visual imagination, perhaps due to their powerful representational qualities. Office meetings, elevator or subway rides seem to be significantly riskier from a public health perspective, but they also have far less iconic potential. These activities in poorly lit indoor settings are much harder to capture by camera, and it is even more challenging to effectively communicate them to broad audiences. Thus, visually spectacular sites, ideally combined with the image of a partying or otherwise irresponsible "covidiot", provide powerful visuals to capture attention without necessarily representing the core components of the crisis.

When our imagination moves away from the categories of "hero" and "villain", we are often picturing the "stage": the iconic spaces that show the signs of radical change in pandemic times (Fig. 6). Images of the eerily empty Times Square, Eiffel Tower and Taj Mahal remind viewers of how understandings of a "rapid globalization" have changed from one day to the next. Sites that are usually packed with tourists are now left to locals and to some animals that have started to reclaim them. Everyday sites from airports to museums to concert halls are also lacking the buzz they were used to. Non-iconic sites of everyday life, like subways and buses, have lost most of their regular appeal, suggesting a potential shift in how we are going to conduct our future, whether in "post-pandemic" or "living with a pandemic" times.

There are also new sites that are excessively photographed. Make-shift hospitals, for instance in iconic Central Park, serve as key examples. These hospitals, which 
Fig. 6 "An aerial view shows the deserted Place de l'Etoile and the Arc de Triomphe in Paris, during a lockdown imposed to slow the spread of the coronavirus disease (COVID-19) in France, April 1, 2020. Picture taken with a drone April 1, 2020", Pascal Rossignol, Reuters

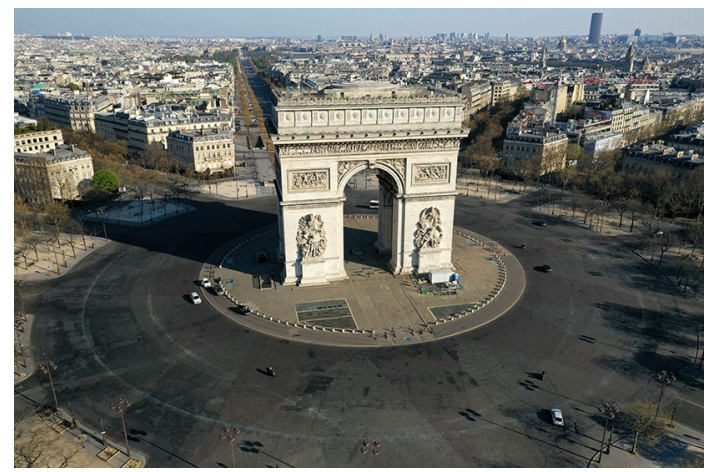

can be white tents, stadiums, dorms and military ships tend to echo the memories of the Superdome that has become one of the infamous iconic sites of the Katrina disaster in the United States (Eyerman 2015). In particularly hard-hit areas of the world, hospital corridors, exam rooms and other make-shift spaces have also become key sites of the crisis. But medical privacy concerns do not permit adequate access for photographers to human suffering in these spaces, rendering the makeshift hospital photographs, with a few notable exceptions, mostly empty and similar to spectacular architectural images.

Since what we can photograph outside is limited, our visual attention often turns to our domestic sites instead: the only space to which we still have unlimited access. A powerful example is a very popular international Facebook group, "The View From My Window" that asks people to post pictures of their apartment views, and accompany these photographs with short narratives. Facebook users in their comments celebrate the views and also add where they are posting their notes of admiration from, presenting themselves as part of a caring and beautiful "global village". But most posted photographs seem too perfect to be true, suggesting that even in this case social media tempt people to show a better-than-real-life version of themselves, or the site evoked responses mostly from that minority of people who have really great apartment views. Some also pushed back against this "perfect" view of the world, writing about various hardships people face during the pandemic (Fig. 7).

Leading photographers from Tehran to Shanghai to Florence have also contributed to this movement on Instagram and other platforms, posting images of their homes and everyday neighborhood walks (Libbey and Farago 2020). Perhaps the most ambitious photographic project so far was the New York Times' "The Great Empty". More than thirty photographers took to the streets all around the world to capture the world as it was changing in front of their eyes. Their images showed empty London during rush hour, a subway without commuters in Munich, boats without passengers in Srinagar, a deserted airport in Tokyo, and an empty hot dog stand in Seattle, among others. The New York Times published a selection of the photographs, introduced by an essay from architecture critic Michael Kimmelman. Kimmelman argued that "[t]hese images are haunted and haunting, like stills from movies about plagues and the apocalypse, but in some ways they are hopeful. They also remind us that beauty requires human interaction" (The New York Times 2020). 
Fig. 7 Photo posted in the "View from My Window" Facebook group. "This is the view from our kitchen window in Chattarpur, New Delhi. We are lucky to live in an apartment with a fridge. The workers next door are also in lockdown but have few savings, no income, no fridge, and no social distance." (Courtesy of Graham R. Hulse, April 19, 2020)

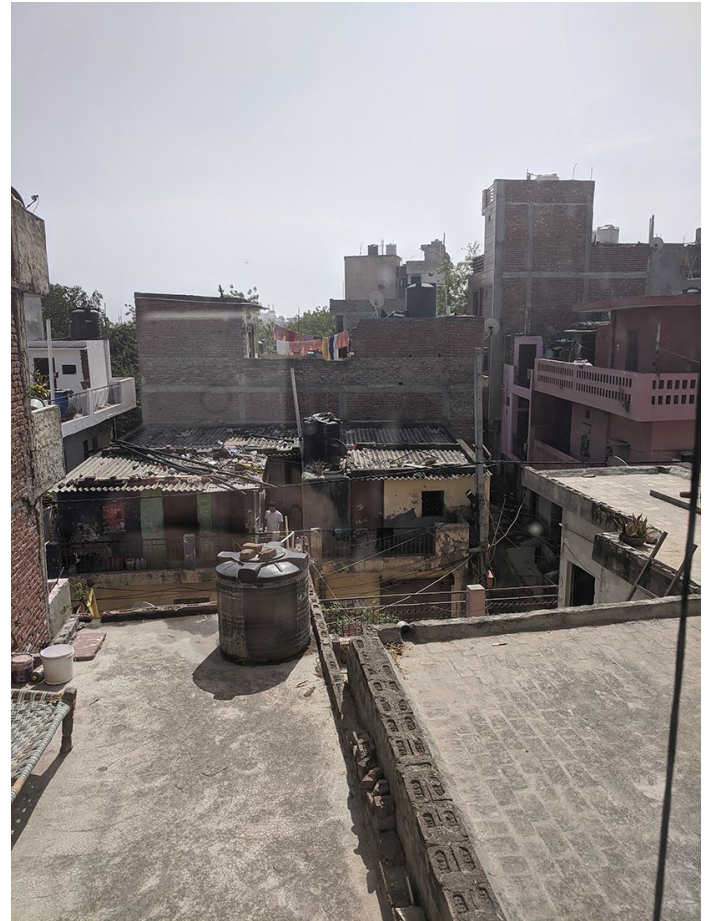

As streets and offices emptied out, our work lives suddenly moved to our domestic spaces, at least this was the experience for many professionals who had the privilege to stay at home. Zoom and other video conferencing software served as connections to the outside world. But they also invited outsiders to our homes. Pets, kids and other family members routinely jumped into the carefully arranged "home offices", making our domestic spaces and lives more visible to outsiders. The famous BBC interview scene, when the interviewed professor's kids unexpectedly entered his office as he was live on television, has become a regular experience for many workers and their colleagues. The changing practices of work were much easier to capture and publish than the horrors of the disease and became a very popular genre in mass media.

Finally, some images of spaces also attempted to grasp the tragedy of the 2020 pandemic. They showed mass graves from Brazil to Iran to the United States. Families on Zoom as they tried to say goodbye to loved ones who were spending their last days alone in hospitals. Refrigerator trucks in front of overflowing hospitals. Packed hospital rooms in Northern Italy. Online mourning and funerals. Some photographs also showed the economic toll the pandemic took on people, for instance, a frequently used genre of photographs displayed people in lines in front of food banks.

All these images of the coronavirus tried to grasp the "essence", the "deep meaning" of the crisis through a particular scene or moment. They were all attempts to touch the general through the particular. Representations of the virus, our actions, heroes, villains and spaces offered the illusion that we see the crisis, even when the key performer, the virus, has remained invisible. Iconic representations as symbolic condensations also - 
summarize more than they actually depict (Sonnevend 2012, 2016). They resemble some aspects of the crisis, but they come to represent something much broader and larger in social life. Their powerful, expressive surfaces become reference points that trigger passionate debates, but sometimes also provide solace. In the case of the 2020 pandemic, images have become our key sources for imagining the crisis. They also offered ways to socially connect in a time of painful and prolonged physical distance.

Acknowledgements I would like to thank the editors and peer-reviewers of AJCS for their very thoughtful and constructive comments, Agnes Szanyi for her invaluable work as my research assistant, and Christel-Ann Augustin, Graham R. Hulse and Drew Harris for generously agreeing to the publication of their photographs and infographics.

\section{References}

Alexander, J.C. 2008. Iconic consciousness: The material feeling of meaning. Environment and Planning D: Society and Space 26 (5): 782-794. https://doi.org/10.1068/d5008.

BBC. 2020. Li Wenliang: Coronavirus death of Wuhan doctor sparks anger. 7 February. https://www.bbc. com/news/world-asia-china-51409801. Accessed 7 Aug 2020.

Britt, R.R. 2020. What the coronavirus image you've seen a million times really shows. Elemental, 13 March. https://bit.ly/2NuDu1e. Accessed 11 June 2020.

Eyerman, R. 2015. Is this America?: Katrina as cultural trauma. Austin: University of Texas Press.

Feng, E. 2020. Millions demand answers in China after doctor's death from coronavirus. NRP, 7 February. https://www.npr.org/2020/02/08/804056722/millions-demand-answers-in-china-after-doctors-death -from-coronavirus. Accessed 7 Aug 2020.

Giaimo, C. 2020. The spiky blob seen around the world: How C.D.C. medical illustrators created the coronavirus pandemic's most iconic image. The New York Times, 1 April. https://nyti.ms/3fRlb2H. Accessed 8 June 2020.

Libbey, P., and J. Farago. 2020. The world's great photographers, many stuck inside, have snapped. The New York Times, 2 April. https://nyti.ms/3dzCqDT. Accessed 9 June 2020.

National Portrait Gallery. 2020. Hold still: A portrait of our nation in 2020. https://www.npg.org.uk/hold-still I. Accessed 3 June 2020.

Prathner, K.A., C.C. Wang, and R.T. Schooley. 2020. Reducing transmission of SARS-CoV-2. Science, advance online publication 27 May. https://doi.org/10.1126/science.abc6197.

Roberts, S. 2020. Flattening the coronavirus curve. The New York Times, 27 March. https://www.nytim es.com/article/flatten-curve-coronavirus.html. Accessed 11 June 2020.

Sonnevend, J. 2012. Iconic rituals: Towards a social theory of encountering images. In Iconic power: Materiality and meaning in social life, ed. J.C. Alexander, D. Bartmanski, and B. Giesen. New York: Palgrave Macmillan.

Sonnevend, J. 2016. Stories without borders: The Berlin wall and the making of a global iconic event. Oxford: Oxford University Press.

The New York Times. 2020. The great empty photographs by The New York Times. (Introduction by Michael Kimmelman). 27 March. https://nyti.ms/3eyWho4. Accessed 11 June 2020.

Weinberg, A. 2020. The "flatten the curve" chart was ugly and not scientifically rigorous. Why did it work so well? Mother Jones, July/August. https://bit.ly/30magJv. Accessed 1 Aug 2020.

Yu, V. 2020. 'Hero who told the truth': Chinese rage over coronavirus death of whistleblower doctor. The Guardian, 7 February. https://bit.ly/2CvqQgi. Accessed 10 June 2020.

Publisher's Note Springer Nature remains neutral with regard to jurisdictional claims in published maps and institutional affiliations.

Julia Sonnevend is Associate Professor of Sociology and Communication at the New School for Social Research in New York. She is the author of Stories Without Borders: The Berlin Wall and the Making of a Global Iconic Event (Oxford University Press: 2016). 